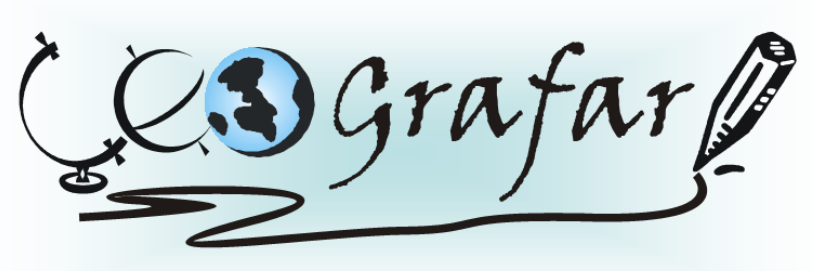

Revista Eletrônica do Programa de Pós-Graduação em Geografia - UFPR

ENSINO DE GEOGRAFIA E O USO DE MULTIMÍDIA INTERATIVA: A CONFECÇÃO DO ATLAS POPULACIONAL DA MICRORREGIÃO GEOGRÁFICA DE SANTA MARIA/RS

TEACHING OF GEOGRAPHY AND THE USE OF INTERACTIVE MULTIMEDIA: MAKING A POPULATION ATLAS FROM THE MICROREGION GEOGRAPHIC OF SANTA MARIA / RS

(Recebido em 05.06.2012; Aceito em 19.01.2013)

Flaviene Valcorte Comin Universidade Federal de Santa Maria Santa Maria, RS, Brasil e-mail: flavienevalcorte@hotmail.com

Vanessa Oliveira da Silva Universidade Federal de Santa Maria Santa Maria, RS, Brasil e-mail:nessa.geo@gmail.com

Mirian Oliveira da Rocha Universidade Federal de Santa Maria Santa Maria, RS, Brasil e-mail: hildamirian@gmail.com

\title{
Resumo
}

Este artigo apresenta o processo de desenvolvimento do Atlas Populacional da Microrregião Geográfica de Santa Maria/RS em multimídia interativa, que tem como finalidade: (a) divulgar os dados do Censo de 2000 através da representação cartográfica e (b) contribuir de forma significativa com o ensino de geografia no ensino fundamental, ressaltando a importância e as potencialidades dos recursos da informática nos processos de ensino e aprendizagem, permitindo maior interação do educando com as informações. Para o ensino da Geografia, tais recursos contribuem para auxiliar a aprendizagem de fatos e fenômenos, que são melhor 
apreendidos a partir de linguagens gráficas associadas a linguagens textuais. A simulação de espaços geográficos por meio do ambiente virtual possibilita a aproximação do educando com seu objeto de investigação, além de democratizar o acesso e aumentar a capacidade de análise sobre informações da região, no caso em estudo, a Microrregião Geográfica de Santa Maria/RS.

Palavras-Chave: Atlas, População, Microrregião Geográfica, Ensino de Geografia, Multimídia.

\begin{abstract}
This article presents the development process of the Population Atlas of Microrregião Geográfica de Santa Maria/RS in interactive multimedia, which aims to: (a) disclose the data from the 2000 Census through the cartographic representation and (b) contribute significantly with the teaching of geography in elementary school, highlighting the importance and potential of computational resources in the teaching and learning, allowing greater interaction with the student information. For the teaching of geography, such features contribute to assist the learning of facts and phenomena, which are best learned from graphical languages associated with textual languages. The simulation of geographic areas through the virtual environment enables the student to approach their object of research, in addition to democratize access and increase the ability to analyze information about the region, in our case, Microrregião Geográfica de Santa Maria/RS.
\end{abstract}

Keywords: Atlas, Population, Microregion Geographic, Geography Education, Multimedia.

\title{
Introdução
}

\footnotetext{
"a história dos mapas confunde-se com a própria história da humanidade, tornando-se por essa razão,um tema inesgotável, bastante amplo e complexo mas, sobretudo, apaixonante pelas surpresas que nos são reveladas a cada documento analisado (Duarte, 2002,p.19)".
}

O desenvolvimento das Tecnologias da Informação e Comunicação (TICs) nas últimas décadas vem afetando todos os setores da sociedade, diminuindo as distâncias, minimizando esforços e tempo nas atividades diárias e, sobretudo, ampliando as possibilidades de acesso à informação. Scaramello (2002) afirma que, no âmbito educacional, a disseminação do uso das TICs tem permitido agilizar os serviços administrativos e elaborar materiais didáticos. No entanto, há uma grande 
expectativa quanto às possibilidades de assessoramento desses recursos no processo de ensino e aprendizagem, o que irá produzir grande impacto no aprender a aprender.

Com o surgimento da tecnologia multimídia, os recursos didáticos tornaramse mais interativos, pois a utilização de diferentes canais como áudio, vídeo e textos permitem que os professores levem em consideração os diferentes estilos cognitivos do educando, tornando a aprendizagem estimulante, atraente e divertida.

Neste contexto o presente artigo busca apresentar o desenvolvimento do Atlas Populacional da Microrregião Geográfica de Santa Maria-RS como uma ferramenta no ensino de Geografia, utilizando-se de recursos de programação, com a finalidade de divulgar os dados do Censo de 2000 através da representação cartográfica possibilitando democratizar o acesso e aumentar a capacidade de análise sobre informações da região, no caso, da Microrregião Geográfica de Santa Maria/RS.

Salienta-se que o atlas multimídia é um recurso educacional que contribui para aprendizagem, pois motiva e "convida" os educandos à prática de relacionar as representações espaciais, e também oportunizar a aprendizagem de fatos, fenômenos e eventos que são melhor apreendidos a partir de linguagens gráficas associadas a linguagens textuais. A simulação do espaço vivido por meio do ambiente virtual possibilita a aproximação do educando com seu objeto de investigação, permitindo que o aluno desenvolva maior interesse pelo estudo do espaço geográfico.

\section{As Tecnologias da Informação e Comunicação (TICs) na Educação}

É inegável a presença da informática em todos os setores da vida social. Na educação não é diferente. A informática penetrou nas instituições de ensino de tal forma que não é mais possível a escola ignorar a sua existência. Mendelsohn (1997) afirma que as crianças nascem em uma cultura em que se clica, e o dever dos professores é inserir-se no universo de seus alunos, de forma contextualizada. 
O desenvolvimento científico e tecnológico que estamos vivenciando, induz um "encurtamento" das distâncias, permitindo maior contato entre as pessoas e com isso, uma vasta e ampla troca de informações. Segundo Castells (1999), nossa cultura material é transformada pelos mecanismos de um novo paradigma tecnológico que se organiza em torno da tecnologia da informação. Diante disso, ampliam-se o uso de tecnologias como ferramentas educacionais nas escolas, tais como, softwares, Internet, multimídia, entre outros.

Essa concepção já vem sendo experimentada em várias escolas brasileiras e já recebe o incentivo do Governo. Um exemplo disso, é o Programa Nacional de Informática na educação (Prolnfo), órgão do Ministério da Educação e Cultura que pretende instalar 54.097 laboratórios de informática nas escolas públicas. Além disso, serão ofertados cursos para a capacitação de professores. Outro exemplo é a Rede Interativa Virtual de Educação (RIVED), programa da Secretaria de Educação à Distância (SEED), que tem por objetivo produzir conteúdos pedagógicos digitais gratuitos na forma de Objetos de Aprendizagem.

Porém, essas mudanças paradigmáticas no ensino, requerem a compreensão do papel do currículo e disciplinas escolar e da didática para a construção da aula. Nessa perspectiva, torna-se essencial a adaptação desses recursos para o usuário e o público alvo, além das teorias educacionais e conceitos que embasam a aprendizagem e a construção do conhecimento pelo aluno.

Para o ensino da Geografia, os recursos tecnológicos digitais devem estimular a análise do espaço geográfico por meio dos conteúdos adaptados, que promovam um "desvelamento" da realidade, o desenvolvimento do raciocínio espacial e das habilidades de pensamento.

\section{A criança, a Geografia e a representação do espaço}

Para entender como ocorre a relação da criança com a representação do espaço, é necessário algumas reflexões: Qual é o espaço percebido pela criança? Como ela percebe este espaço? Como ocorre a representação deste espaço? Que importância tem para a Geografia? Estes questionamentos e outros tópicos 
referentes à concepção de espaço são importantes para o aluno, tendo em vista sua relevância para a compreensão dos elementos geográficos.

Segundo LE SANN (2007, p. 113).

\begin{abstract}
Esta é a primeira noção caracteristicamente Geográfica. Varia do espaço local ao sideral, em função da escala. O espaço é percebido por meio da observação, seguida pelo seu registro, num primeiro momento sobre a forma de desenho, num segundo momento, por uma representação, ou seja, um desenho fiel à realidade
\end{abstract}

Para adquirir noções espaciais e fazer a relação com os demais fenômenos geográficos, várias fases do desenvolvimento e da aprendizagem devem ser consideradas. No início, o espaço é muito limitado, pois a criança precisa descobrir o corpo, só depois percebe o espaço exterior e assim vai ampliando sua percepção. Para que ocorra a conscientização do espaço ocupado pelo próprio corpo, há dois processos essenciais: o esquema corporal, período em que a criança é muito egocêntrica e vê tudo a partir de si, e a lateralidade, quando a criança adquire o domínio de um dos lados para se orientar espacialmente. Segundo ALMEIDA; PASSINI (2004, p.11), "desde os primeiros meses de vida do ser humano delineiamse as impressões e percepções referentes ao domínio espacial, as quais se desenvolvem através de sua interação com o meio".

A evolução das formas de percepção do espaço passa por três dimensões principais: o espaço vivido, o espaço percebido e o espaço concebido. Primeiramente a criança entra em contato com o espaço em que vive, recorrendo aos movimentos diversos: anda, salta, corre e começa a diferenciar as distâncias entre objetos e sua relação. Ela usa seu corpo como referencial para explorar as relações espaciais, nota as diferenças entre perto/longe, em cima /embaixo. Nesta fase ela é capaz de descobrir o espaço da sala de aula ou da rua onde vive.

A segunda dimensão refere-se ao espaço percebido, quando a criança já consegue conhecê-lo, sem ter que experimentar como no estágio anterior. A obtenção do domínio espacial, seguindo os conceitos acima/abaixo, na frente/atrás, conduz a criança a identificar alguns termos como dos pontos cardeais e entender a 
organização de espaços mais amplos como do bairro, do município até do continente.

Dessa forma, o domínio do espaço vivido prepara a criança para o entendimento do espaço percebido, que pode ser apresentado sob a forma de uma paisagem ou de um documento impresso, como por exemplo o mapa. Pode-se considerar que é nesse momento que começa o entendimento da Geografia propriamente dita.

Quando ele já domina o espaço percebido, torna-se apto à última dimensão, que é do espaço concebido ou das formas. Os objetos já não são percebidos somente por sua concretude, mas pelas representações entre eles e seu conteúdo. Essa fase extrapola o nível geográfico e está mais próxima do domínio matemático.

Segundo Piaget, a construção do espaço processa-se através de etapas, caracterizadas em estágios e sub estágios (PAGANELLI, 2007). Sua elaboração inicia no nível concreto e, progressivamente, passa para o nível mais abstrato. Ocorre através de relações topológicas, projetivas e euclidianas.

No período pré-operatório ou do espaço representativo (2 anos) é possível trabalhar as relações significante/significado, pois a criança já desenvolveu a função simbólica. Nesta fase, já se torna capaz de agir, não somente sobre os objetos reais e concretos no seu tempo perceptivo, como também sobre fatos simbolizados ou mentalmente representados, o que auxiliará na compreensão da legenda para a leitura gráfica.

No estágio das operações concretas (7/8 anos) o desenvolvimento de algumas estruturas mentais leva à compreensão da proximidade e da ordem, auxiliando ao entendimento das relações espaciais topológicas (espaço vivido), que são auxiliares para a compreensão de limites e fronteiras, assim como da organização do espaço e na leitura de mapas. Nesse momento, é necessário que a criança tenha algum domínio dos conceitos geográficos.

ALMEIDA; PASSINI ( 2004, p. 33) afirmam que

No entanto, a localização geográfica constrói-se à medida que o sujeito se torna capaz de estabelecer relações de vizinhança (o que está ao lado), separação (fronteira), ordem (o que vem antes e depois), envolvimento (o espaço está em torno) e continuidade (a que o recorte do espaço a área considerada corresponde) entre os elementos a serem localizados 
No estágio intermediário a criança consegue libertar-se do seu egocentrismo espacial, coordenar pontos de vistas, conservar formas, descentralizar espaços e construir as relações espaciais projetivas (espaço percebido), passando a ter possibilidades de ler e compreender projeções cartográficas e entender a orientação geográfica. $O$ espaço não precisa ser mais experimentado fisicamente. A criança observa-o, mas ainda tem dificuldade de representá-lo no mapa, pois essa ação exige um grau de abstração que ela ainda não possui. As atividades propostas devem desenvolver conceitos e noções, ao invés de conteúdos sistematizados.

O estágio das coordenações operatórias (11/12 anos) é a fase em que os sistemas podem ser pensados simultaneamente, caracterizando as operações formais. Ao construir as noções de proporcionalidade, horizontalidade, verticalidade, a criança pode elaborar as relações espaciais euclidianas (espaço concebido), sendo passíveis de entendimento os conceitos de escala, e coordenada geográfica, abrindo possibilidades para ler mapas murais e o Atlas. É possível à criança, neste momento, estabelecer relações espaciais entre os elementos através de sua representação. Isto é, mostra-se capaz de imaginar uma área sem tê-la conhecido.

Portanto, os conceitos geográficos, a noção de espaço e a aplicação dos princípios gráficos serão mais eficazes se forem consideradas as fases de evolução da criança no seu desenvolvimento como um todo: cognitivo (idade), motor (físico) e intelectual (aprendizado).

\section{Atlas Multimídia}

Joly (1985, p.7) conceitua mapa como sendo "uma representação geométrica plana, simplificada e convencional, do todo ou de parte da superfície terrestre, numa relação de similitude conveniente denominada escala". Duarte (1991) define como sendo uma representação gráfica, que geralmente retrata uma superfície plana e em determinada escala de características naturais e artificiais, terrestre ou subterrânea.

Segundo Oliveira (1988) o mapa temático é um documento em quaisquer escala em que, sobre um fundo geográfico básico são representados os fenômenos 
geográficos, geológicos, demográficos, econômicos, agrícolas, entre outros, visando o estudo, à análise e à pesquisa dos temas, no seu aspecto espacial. O objetivo dos mapas temáticos para JOLY (1988, p.73),

\begin{abstract}
O objetivo dos mapas temáticos é o de fornecer, com o auxílio de símbolos qualitativos e/ou quantitativos dispostos sobre uma base de referência, geralmente extraída dos mapas topográficos ou dos mapas de conjunto, uma representação convencional dos fenômenos localizáveis de qualquer natureza e de suas correlações. Salienta que os mapas temáticos são inumeráveis, pois eles tocam a tudo aquilo que apresentam algum aspecto de repartição no espaço atual, passado ou futuro.
\end{abstract}

Segundo Madruga (2006) os temas são apresentados de forma a facilitar a identificação e melhor visualização dos elementos, sendo estes convencionados utilizando-se simbologia adequada, prática e objetiva.

Os mapas temáticos na sua multiciplidade, muitas vezes são considerados como objetos geográficos, ao mesmo tempo em que o geógrafo é tido como o especialista mais competente para esta tarefa. Essa concepção parece exagerada. $\mathrm{Na}$ realidade, os mapas temáticos interessam à geografia na medida em que, não só abordam conjugadamente um mesmo território, como também o consideram em diferentes escalas (MARTINELLI,1991, p. 35).

Baseado nessas concepções, tem-se a definição do conceito de atlas, que por definição é um conjunto de mapas ou cartas geográficas. Porém o termo também se aplica a um conjunto de dados sobre determinado assunto, sistematicamente organizadas e servindo de referência para a construção de informações de acordo com a necessidade do usuário. De acordo com Oliveira (1988) o dicionário cartográfico registra Atlas como sendo uma coleção ordenada de mapas, com a finalidade de representar um espaço dado, e expor um ou vários temas.

Atualmente, com o desenvolvimento das técnicas cartográficas, o aperfeiçoamento da fotografia a aviação e a informática, a cartografia dá um salto. Os mapas e cartas que cada vez mais são utilizados eletronicamente, descartando a necessidade de impressão e tornando-os interativos. Os mapas, antiga e tradicionalmente feitos usando material de escrita, a partir do aparecimento dos

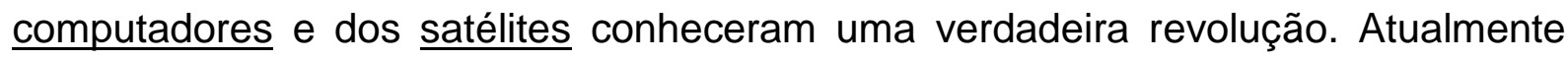


são confeccionados utilizando-se softwares próprios, por meio do Sitema de Informações Geográficas (SIGs) ou softwares especializados em ilustração para mapas. Os dados assim obtidos ou processados são mantidos em base de dados.

Cassol (2008), afirma que o crescimento da utilização dos SIG's ocorre pois, facilitam o processo que aquisição de informações e dados e também a representação desses dados de forma planimétrica e automatizada, mas principalmente, tornam os produtos e mapas mais acessível aos usuários. Dentre esses mapas, destacamos os interativo e em multimídia.

Ramos (2005) afirma que é necessário compreender o uso da cartografia digital e também de os SIGs como subsídio para a elaboração de mapas estruturados para consulta em ambientes digitais interativos, ou seja, mapas elaborados para serem instrumentos de análise exploratória. Especificamente para multimídia, Ramos (2005) afirma que essa conceituação é "redundante", pois usa o termo multi junto com mídia, e assim implica a mistura de "meios", incluindo imagens, vídeos, slides e áudios, entre outros.

Programas de multimídia tem a vantagem de envolver múltiplos sentidos simultaneamente, e assim, acomodar uma grande variedade de estilos de aprendizagem. (NASCIMENTO, 2012).

Para Audino (2012), é fundamental que o usuário tenha o poder de decidir a sequência e navegação pelo Atlas. Essa autonomia ainda the dá direito de estabelecer associações e interligações entre informações diversas, mesmo que de natureza diferente (textos, imagens e sons, por exemplo), progredindo de um assunto ao outro, sem perder o contexto ao qual está inserido.

Dessa forma, os Atlas em multimídia, permitem que o usuário interaja ativamente com os dados e a informaçõe a ele apresentados, por meio de busca, exploração e análise, permitindo assim a aquisição de novos conhecimentos. 


\section{Desenvolvimento do Atlas populacional da Microrregião Geográfica de Santa Maria/RS}

O desenvolvimento do Atlas iniciou a partir da observação em escolas e conversas com professores, onde constatou-se a escassez de materiais cartográficos, principalmente voltados à realidade local e no contexto da Geografia Escolar no Ensino Fundamental. Nessa etapa da escolarização, a utilização do lugar como base da reflexão geográfica, é essencial na construção do instrumental teórico e sua recorrência nos diversos assuntos trabalhados, pois demonstra na prática, um dos pressupostos do processo de ensino e aprendizagem da geografia - a transição local/global e global/local- necessária ao entendimento das diversas realidades de forma integrada e interdependentes.

O estudo das representações cartográficas no Ensino Fundamental, contribui não apenas para que os alunos compreendam os mapas, mas também desenvolvam capacidades relativas à representação do espaço. Os alunos precisam ser preparados para que construam conhecimentos fundamentais sobre essa linguagem, como pessoas que representam, codificam o espaço e como leitores, das informações expressas. Nesse contexto adotou-se a metodologia da semiótica proposta por Simielli (1991), que transcodifica a linguagem escrita para sua representação gráfica. Como propriedades de percepção visual, nos sistemas onde os sinais acumulam significados e com objetivo de tornar mais acessível a interpretação de dados nos mapas.

Em um segundo momento, definiu-se a região da Microrregião Geográfica de Santa Maria que possui $11.736,324 \mathrm{Km}^{2}$ de superfície territorial, fazendo parte da Mesorregião Centro Ocidental Rio-Grandense, encontra-se situada no Estado do Rio Grande do Sul, sendo composta por 13 municípios, sendo eles: Cacequi, Dilermando de Aguiar, Itaara, Jaguari, Mata, Nova Esperança do Sul, Santa Maria, São Martinho da Serra, São Pedro do Sul, São Sepé, São Vicente do Sul, Toropi e Vila Nova do Sul, como mostra a Figura 1. 


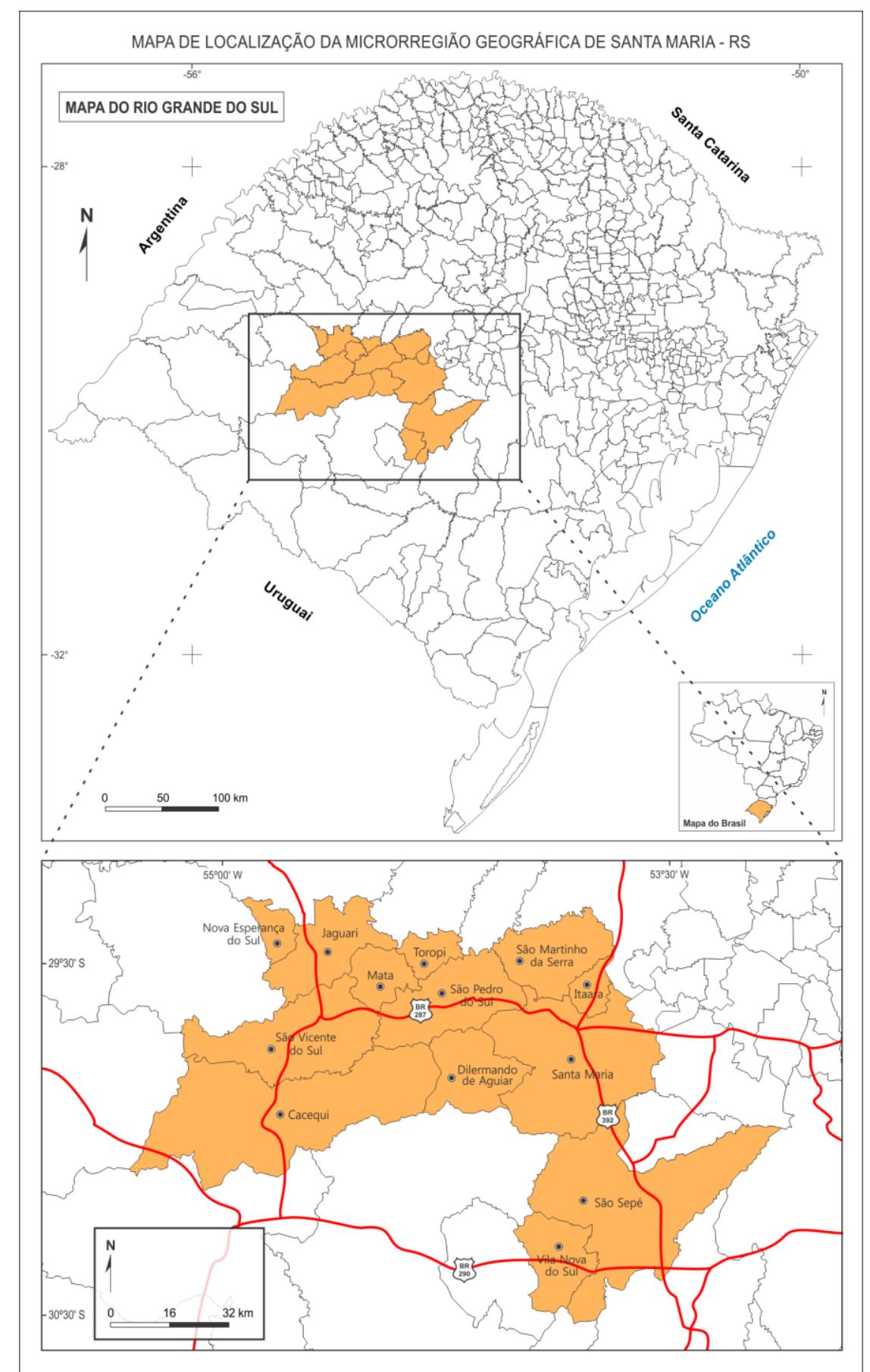

Figura 1 - Localização da MRG de Santa Maria - RS.

Elaboração - AUDINO, D. F; AUTOR. 2010.

Fonte - Instituto Brasileiro de Geografia e Estatística (IBGE), 2010.

Em seguida, iniciou-se o processo de desenvolvimento do atlas, a partir da elaboração de 32 mapas temáticos da Microrregião Geográfica de Santa Maria/RS, organizados de acordo com suas temáticas e separados por faixas etárias, sexo e situação alfabetizados, sendo eles: Mapa de localização; Mapa da área territorial; Mapa da População Total; Mapa da População Urbana; Mapa da População Rural; 
Mapa da População Masculina; Mapa da População Feminina; Mapas da População residente de 1 a 80 anos (divididos com espaço de tempo de 4 anos) e Mapa da População Residente de 5 anos ou mais alfabetizada. Na confecção do Atlas esses mapas estarão.

Para que se desenvolvesse a multimídia interativa, foi utilizado recursos da linguagem da programação, sendo que a plataforma base para o Atlas foi 0 programa Macromedia Flash, que possui ferramentas de edição de áudio, vídeo, texto e interatividade, além de desenvolver animações, aplicações e outros produtos interativos. Este possui uma linguagem de programação simplificada denominada Actionscript que permite a compatibilidade dos dados em qualquer sistema operacional, como por exemplo, Windows e Linux. Com esse programa foi possível montar o layout do Atlas, bem como a animação.

Através dos procedimentos desenvolvidos obteve-se o Atlas Populacional da Microrregião Geográfica de Santa Maria/RS, em Multimídia Interativa. Dessa forma, disponibilizou-se um material que vem a auxiliar no ensino de geografia, bem como, contribuir para que a comunidade seja ela escolar ou não tenha acesso aos dados do Censo Demográfico de 2000, referentes a populaçao de forma espacializada, facilitando o entendimento e a leitura dos dados, conforme observa-se na Figura 2.

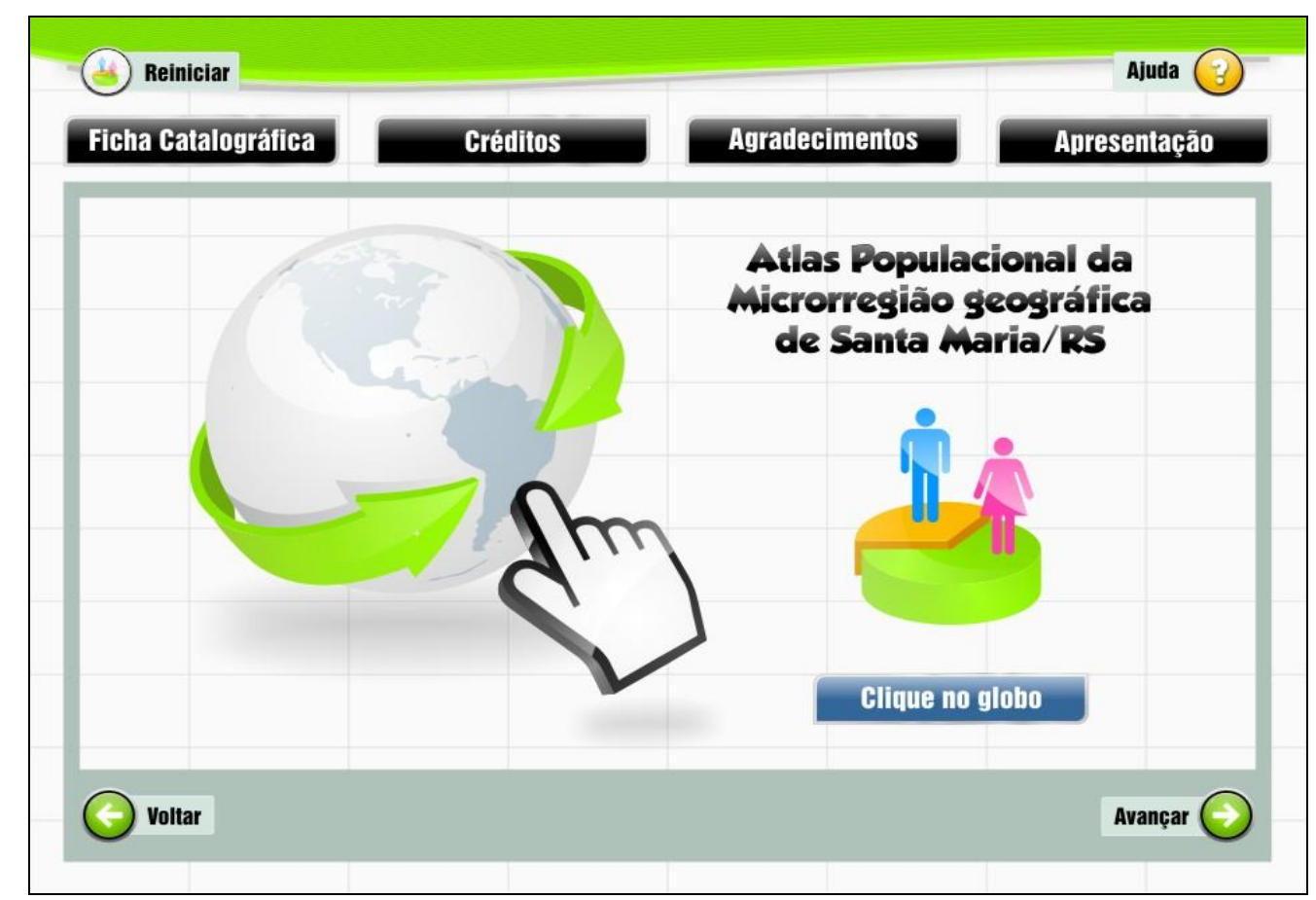

Fig.2 - Tela inicial do Atlas Populacional da Microrregião Geográfica de Santa Maria /RS. 
$\mathrm{Na}$ tela seguinte (Figura 3), o aluno usuário encontra a introdução ao Atlas, por meio dos Créditos, a apresentação, os agradecimentos, além da localização da Microrregião, em diferentes Escalas cartográficas de analise (do global ao local).

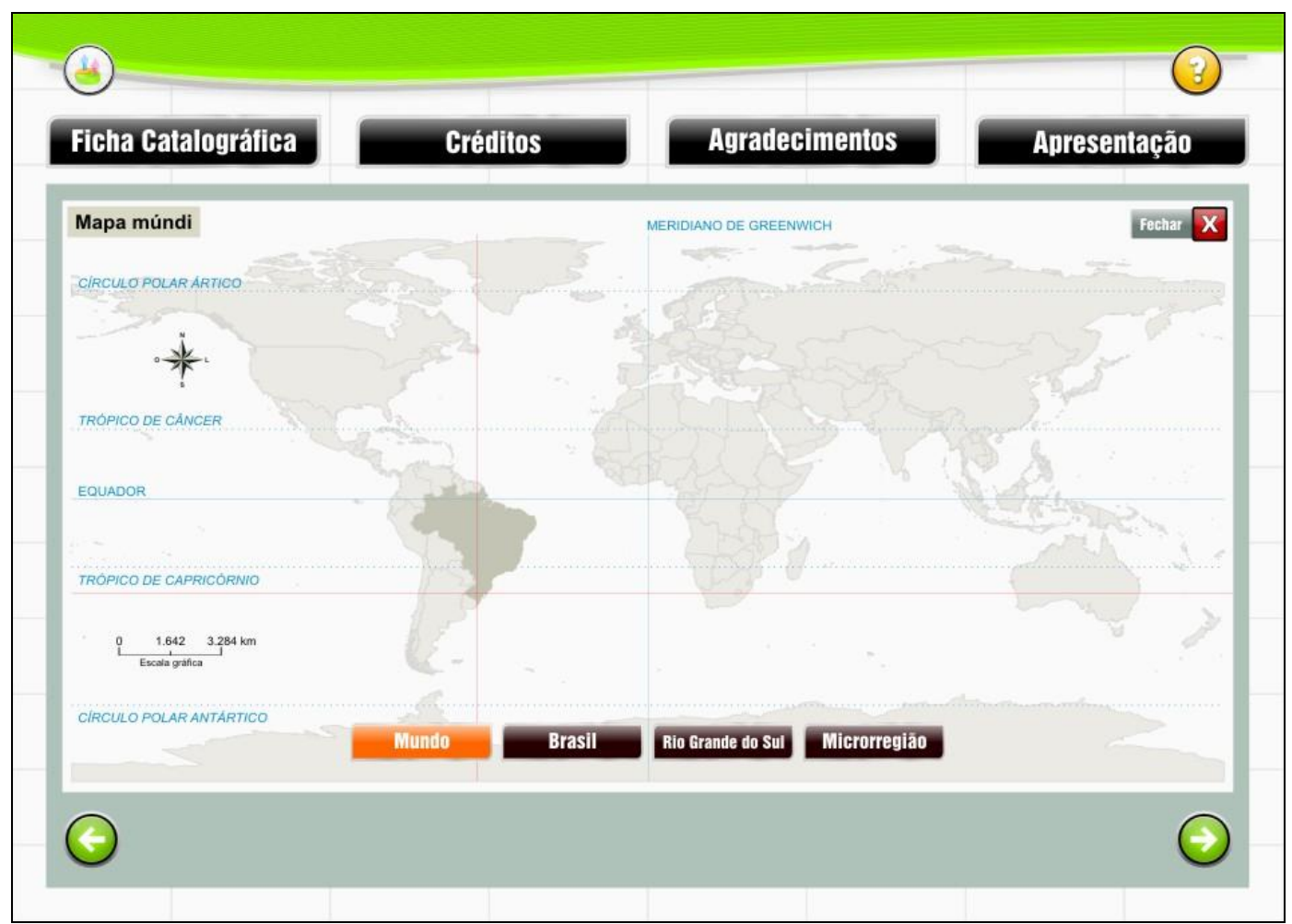

Fig.3 - Tela referente ao módulo localização da Microrregião Geográfica.

O atlas foi dividido em temáticas disponíveis para o inicio da navegação e seleção do alunos, através de elementos linkáveis, sendo eles: Sumário, Histórico, Imagens e Características (FIGURA 4).

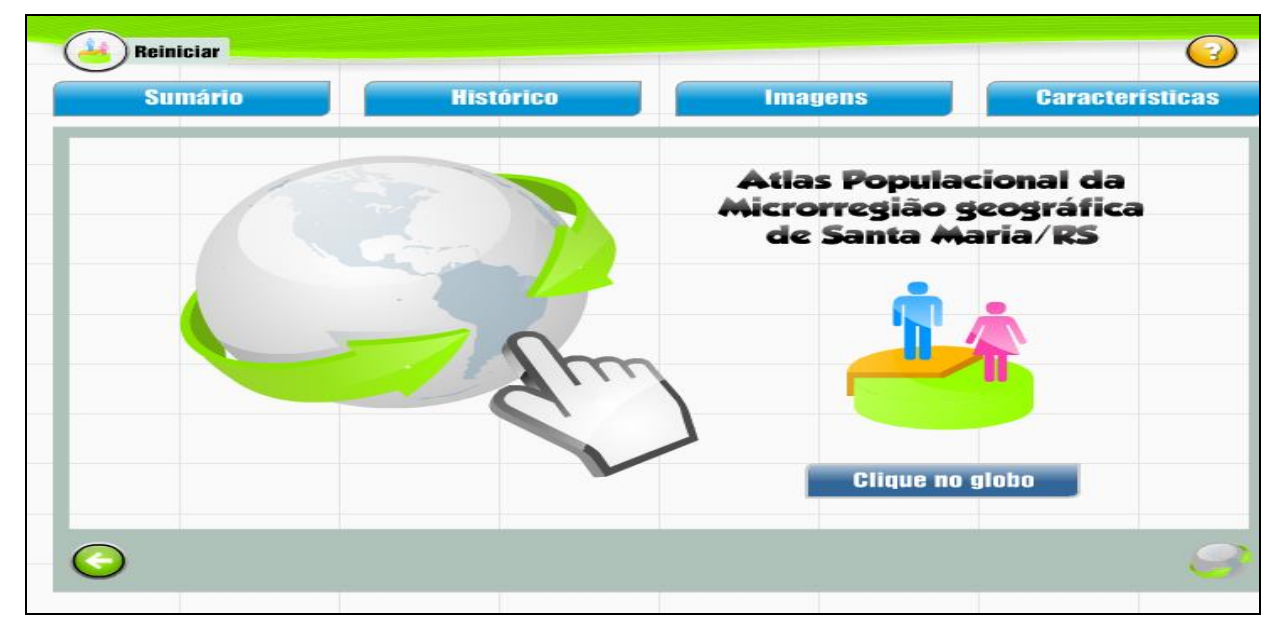

Fig. 4 - Tela referente aos módulos. 
Ao clicar no sumário, o aluno terá disponíveis as temáticas representadas cartograficamente por meio de mapas, sendo elas a Área Territorial, População, Faixa Etária, Educação.

ÁREA TERRITORIAL - apresentou-se a área territorial de cada municipio em $\mathrm{Km}^{2}$ (FIGURA 5).

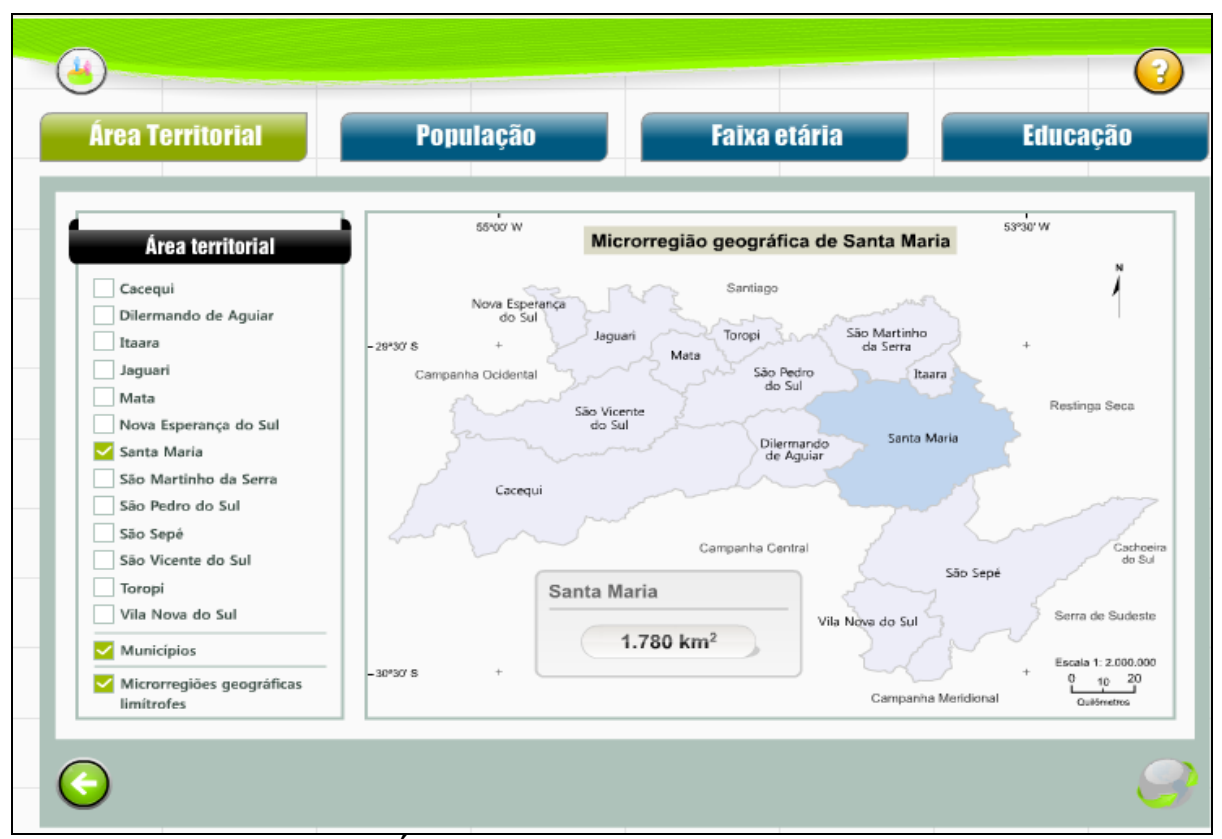

Fig. 5 - Tela referente a Área territorial dos municípios da MRG.

POPULAÇÃO: nesse momento trabalhou-se com definições de população total, urbana, rural e residente, por meio de mapas temáticos coropléticos, com as diferenças e características expressas na legenda (FIGURA 6). Essa temática pode ser trabalhada em sala de aula por meio de conteúdos contextualizados e questionamentos como: qual o municipio que apresenta mais população urbana? qual consequência de se ter alta população urbana? 


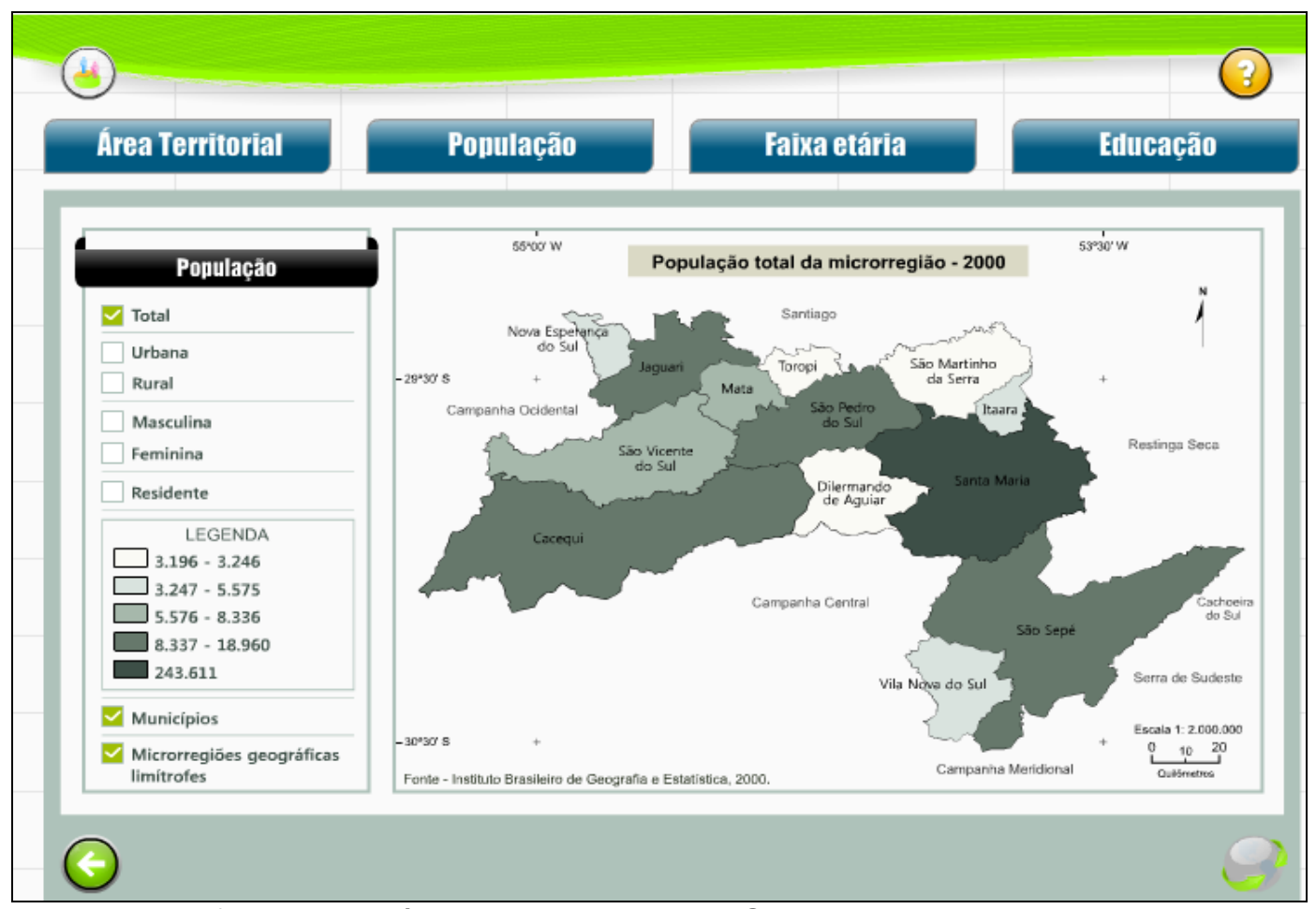

Fig. 6- Tela referente ao módulo população da MRG.

FAIXA ETÁRIA: seguiu-se a mesma abordagem anterior, porém dividindo a população residente em diferentes faixas etárias (FIGURA 7). Essa temática permite reflexões como a importancia do planejamento de cada município.

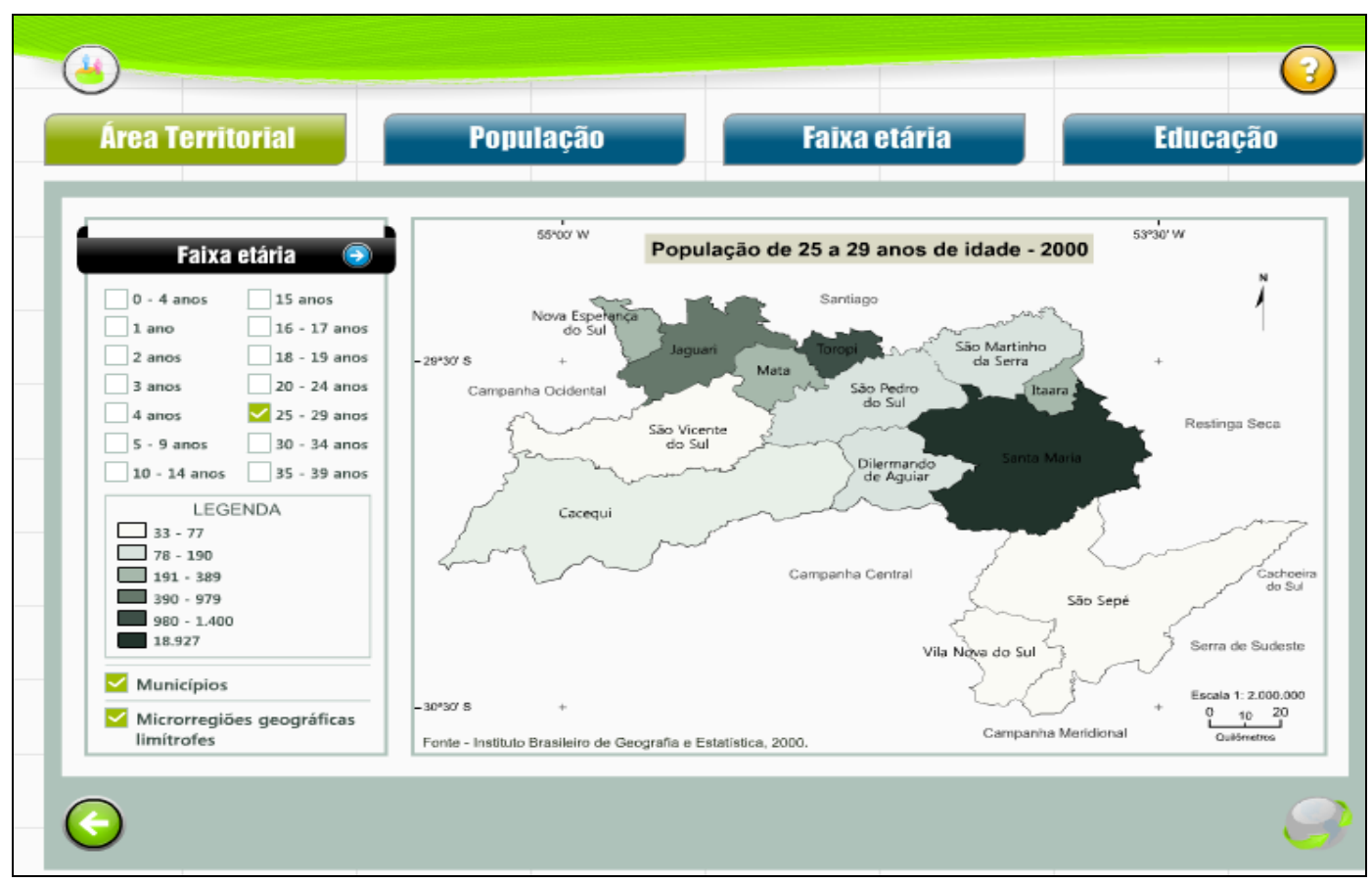

Fig. 7 - Tela referente a faixa etária da população da MRG. 
EDUCAÇÃO: esse módulo apresenta um mapa da população com 5 anos alfabetizada (FIGURA 8). O objetivo desse mapa, é contextualizar com a realidade do aluno, fazendo com que ele se sinta parte integrante da relação entre a sociedade/natureza, entendo como se representa os fenômenos espaciais, tonando possivel as compreenção cartográfica e o o objetivo principal da geografia escolar, além de destacar a importancia do planejamento na área de ensino.

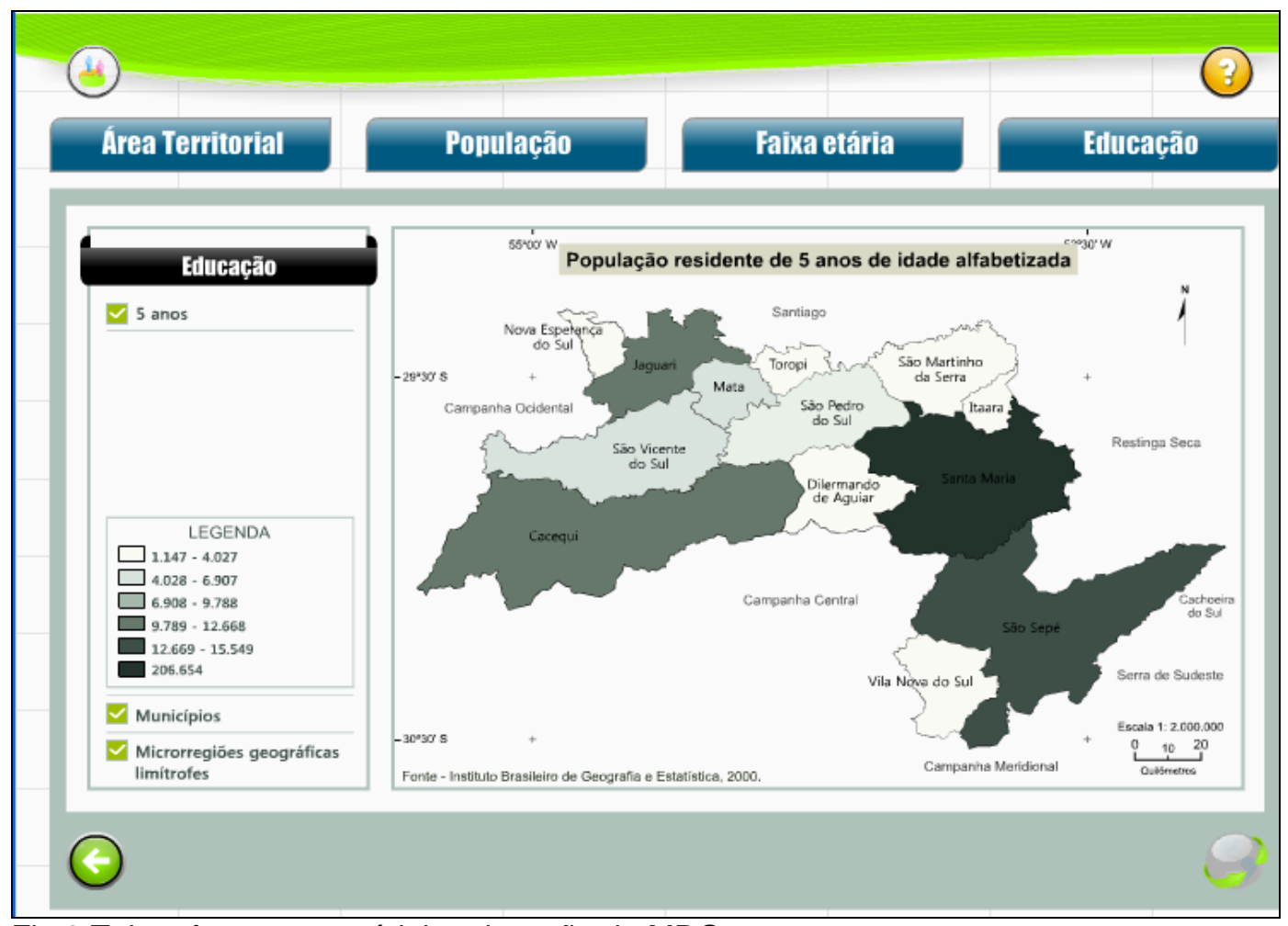

Fig.8 Tela referente ao módulo educação da MRG.

Retornando a tela inicial, o alunos terá disponível o link HISTÓRICO, onde apresenta telas referentes ao histórico dos municipios que compoe a Microrregião, conforme observamos na Figura 9, o histórico do município de Santa Maria. 


\section{Santa Maria}

Sob o aspecto lendário, diz a Lenda de Imembuí que Santa Maria nasceu do amor da índia Imembuí, da tribo dos Minuanos, pelo guerreiro português Rodrigues, feito prisioneiro pelos índios e pede por sua vida. Seus descendentes teriam dado início ao povoamento de Santa Maria, chamando-a carinhosamente de Ybitory Retan (terra da Alegria). Hoje, Santa Maria é conhecida como a "cidade universitária" ou "cidade da cultura".

A cidade foi criada a partir de acampamentos de uma comissāo demarcadora de limites entre terras de domínio espanhol e português que passavam pela regiăo, em 1797. Durante a Revoluçăo Farroupilha chegaram os primeiros imigrantes alemães, provenientes de São Leopoldo, buscando se afastar dos combates.

De 1801 a 1803 recebeu Santa Maria um contingente de índios, cerca de cinqüenta familias de guaranis, descendo das Missöes orientais, vieram ali levantar seus ranchos em um descampado que é hoje a Av. Presidente Vargas, que também já se denominou Rua Ipiranga. Na época o lugar que ocuparam era chamado simplesmente de Aldeia. Santa Maria da Boca do Monte era parte integrante de Cachoeira, e sua população estava computada junto totalizando 8.225 habitantes - neste número, Santa Maria contribuía com cerca de 800 habitantes. Em 1835, Santa Maria marchava em vertiginoso progresso. Seu comércio e indústria pastoril desenvolviam-se prodigiosamente, e já nesta época a população era calculada em 2290 habitantes. Por lei provincial $n^{\circ} 6$ de 17 de novembro de 1837 foi criada a freguesia de Santa Maria da Boca do Monte, passando por isso o curato a Paróquia, o que quer dizer que deixava de ser capela Curata filial da matriz de Cachoeira para ser também Matriz. Por lei provincial n 400 de 16 de dezembro de 1857, a freguesia de Santa Maria da boca do Monte foi elevada a categoria de vila, sendo em 17 de maio de 1858 instalado o novo município.

Fig.9 - Tela referente ao histórico dos municípios.

No módulo IMAGENS, o aluno observa imagens que destacam os principais pontos turisticos dos municipios (FIGURA 10).

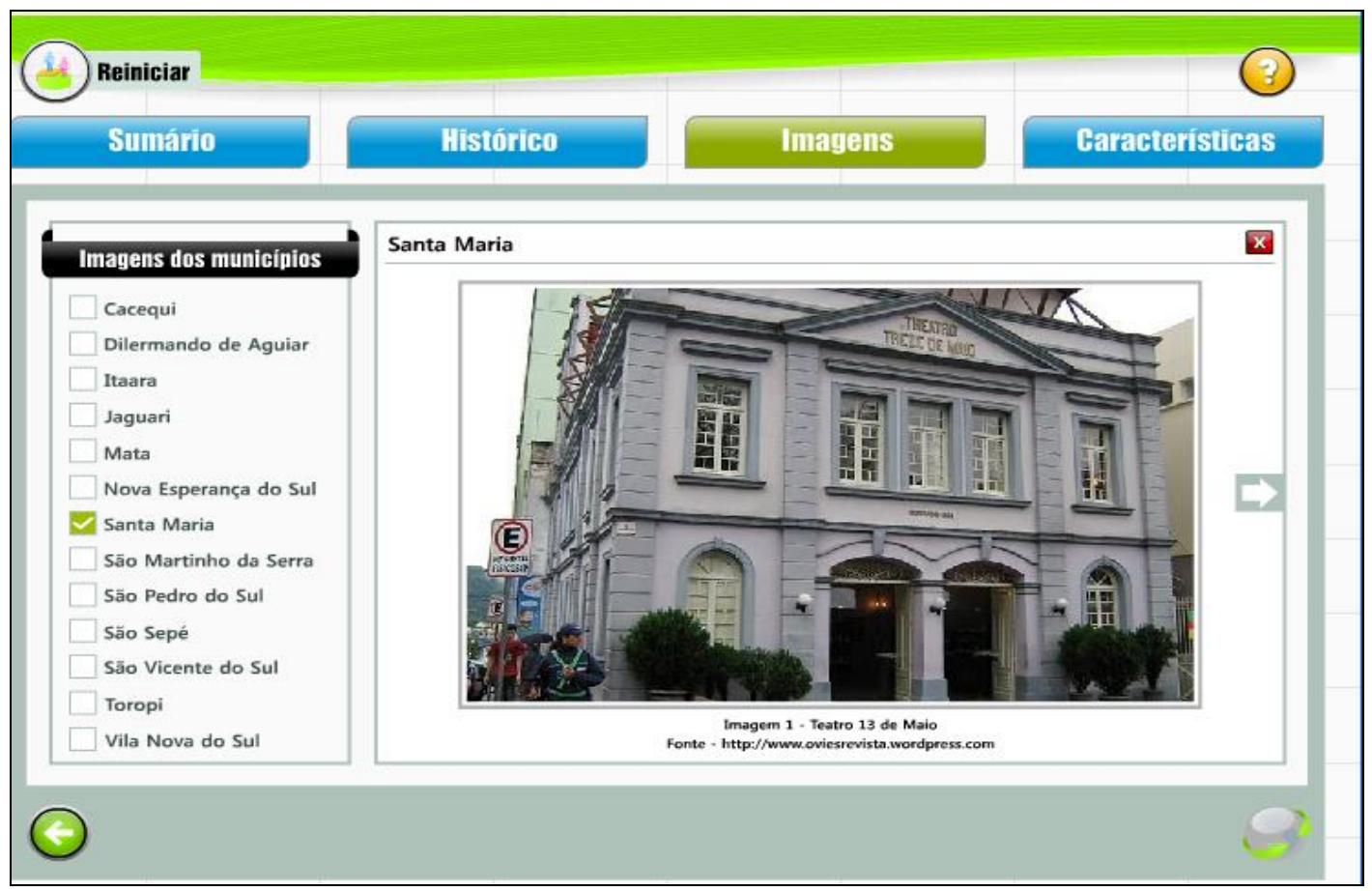

Fig. 10 - Tela referente às imagens dos municípios da MRG. 
E por último, apresenta-se o módulo CARACTERISTICAS, onde realiza-se um apanhado geral das principais caracteristicas, tais como data e leis de criação do municipio, municipio de origem, distância do município de origem, até a capital do Estado Porto Alegre, as vias de acesso e o clima (FIGURA 11).

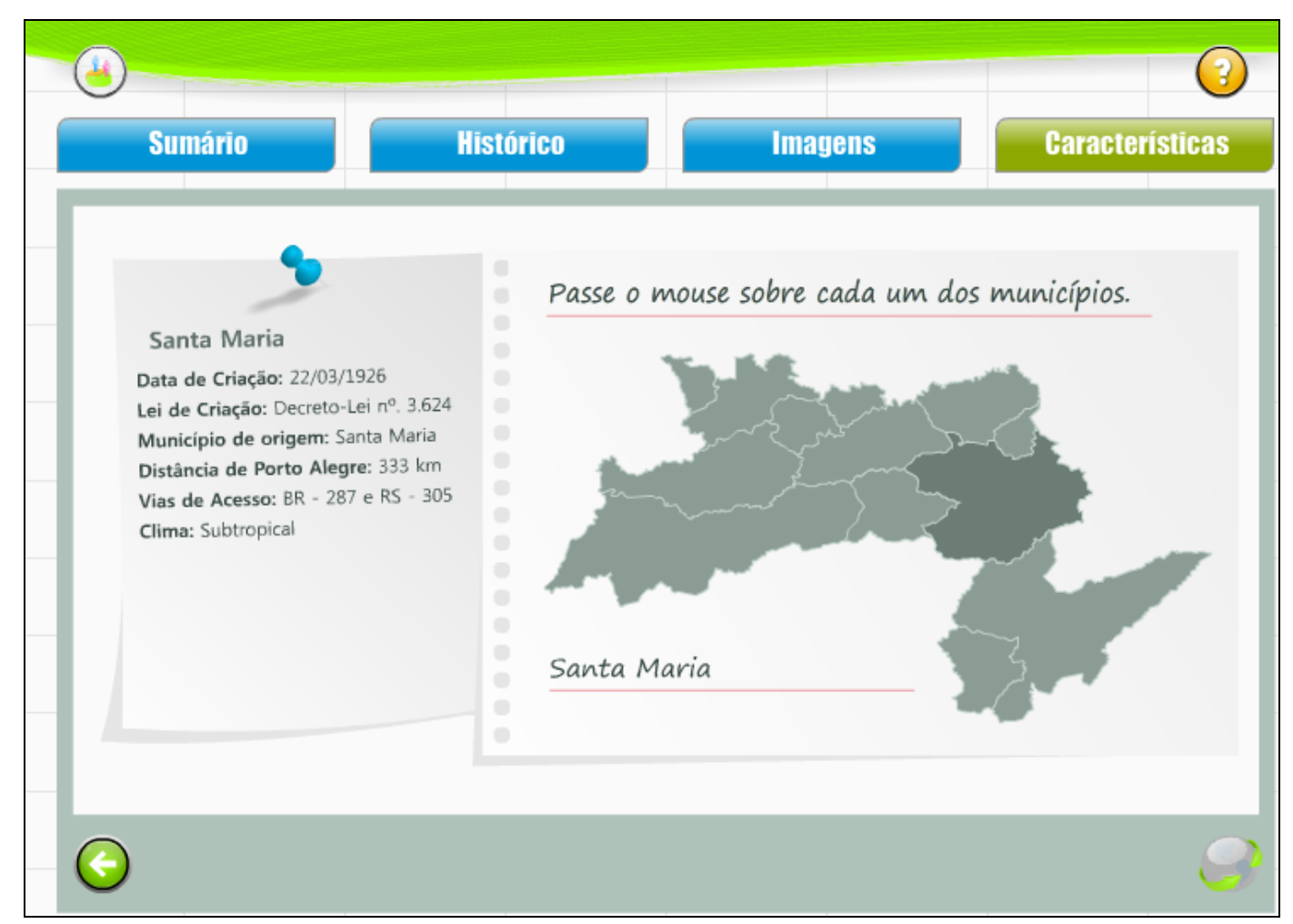

Fig.11 - Tela referente as características da MRG.

Com a finalização do Atlas, pode-se disponibilizar uma ferramenta que auxilia no ensino de geografia, uma vez que, tem-se um instrumento facilitador do ensino e aprendizagem além de demonstrar aos docentes como a ferramenta da Informática pode ser um valioso recurso, capaz de tornar o processo de ensino-aprendizagem mais dinâmico e prazeroso ao aluno. Entende-se que esta contribuição permitiu melhor compreensão sobre a dinâmica da área em estudo por meio da análise da dinâmica dos processos de crescimento e mobilidade populacional em linguagem clara, concisa e didática para o ensino da Geografia. 


\section{Considerações Finais}

Esse trabalho realizou um resgate teórico sobre um recurso didático para 0 ensino da Geografia. A elaboração de um Atlas Populacional Multimídia possibilita a simulação e interação com o mundo real, além de dinamizar o processo leitor/usuário colocando-se em vantagem em relação aos Atlas impressos. Essa é uma maneira de inovar os recursos didáticos tradicionais, contribuindo para 0 processo de ensino e aprendizagem, utilizando a multimídia e proporcionando um aprendizado lúdico, além de oportunizar o estudo do espaço vivido permitindo que o aluno desenvolva maior interesse pelo estudo do espaço geográfico.

Acredita-se que o uso das novas tecnologias educacionais pode transformar 0 ensino, mas para tanto é necessário que haja maior esforço no sentido de fornecer subsídios teóricos aos docentes para a utilização de tais recursos. Somente dessa forma poderemos contar com professores capacitados diante da utilização dos recursos tecnológicos.

\section{Referências}

ALMEIDA, Rosângela Doin de; PASSINI; E. Y. O Espaço Geográfico: ensino e representação. 15ª ed. São Paulo: Contexto,2004.

AUDINO, Daniel Fagundes. Objetos de aprendizagem hipermídia aplicado à cartografia escolar no sexto ano do ensino fundamental em geografia. Florianópolis. Universidade Federal de Santa Catarina, 2012. (Dissertação, Mestrado em Geografia).

CASSOL,Roberto.etal.Cartografia Digital: Reflexão sobre Conceitos e Usos. Anais...Congresso Brasileiro de Cadastro Técnico Multifinalitário. Florianópolis, 2008.

CASTELLS, Manuel A sociedade em rede - a era da informação: economia, sociedade e cultura. Vol 1. 5. ed. São Paulo: Paz e Terra,1999.

CIROLINI, Angélica. Atlas Eletrônico e Socioeconômico sob a perspectiva da cartografia escolar no Município de Restinga Seca, RS. Santa Maria:

Universidade Federal de Santa Maria, 2008. (Dissertação, Mestrado em Geografia). 
DUARTE, Paulo Araújo. Cartografia temática. Florianópolis: ed. Da UFSC, 1991.

Fundamentos de cartografia. Florianópolis: UFSC, 2002.

OLIVEIRA, Cêurio de. Curso de cartografia moderna. Rio de Janeiro: IBGE, 1988.

JOLY, Fernando. A cartografia. São Paulo: Papiros, 1985.

LE SANN, Janine Gisèle. Metodologia Para Introduzir a Geografia no Ensino Fundamental. In: ALMEIDA, Rosângela Doin. Cartografia Escolar. São Paulo: Contexto, 2007. p. 95-118.

MADRUGA, Pedro Roberto de Azambuja. Mapas necessários para o planejamento municipal.Santa Maria, Departamento de Engenharia Rural, Curso de Engenharia Florestal, 2006.( Apostila Didática - inédito)

MARTINELLI, Marcelo. Curso de Cartografia Temática. São Paulo: Contexto, 1991.

NASCIMENTO, Anna Christina de Azevedo. Princípios de design na elaboração de material multimídia para a Web. Disponível em:

<http://www.nead.unisal.br/files/principios_de_design\%5B3\%5D.pdf>. Acesso em: 20 de maio de 2012.

PAGANELLI, Tomoko lyda. Para Construção do Espaço Geográfico na Criança In: ALMEIDA Rosângela Doin. Cartografia Escolar São Paulo: Contexto, 2007. p. 4370.

PERRENOUD, Philippe. 10 novas competências para ensinar. Porto Alegre: Artes Médicas Sul, 2000.

RAMOS, Cristhiane da Silva. Visualização Cartográfica e Cartografia Multimídia: conceitos e tecnologias. São Paulo: UNESP, 2005.

SCARAMELLO, Juliana Massensini. Atlas digitais escolares: proposta de avaliação e estudos de caso. Disponível em:

<http://www.ensino.eb.br/artigos/artigo_atlas.pdf>. Acesso em Novembro de 2010.

SIMIELLI, Maria Elena. et al. Do Plano Tridimensional: A Maquete como Recurso Didático. In Boletim Paulista de Geografia, No.70, 20 Semestre - São Paulo: AGB, AGB, 1991. 